\title{
Improved detection of biomarkers in cervico-vaginal mucus (CVM) from postpartum cattle
}

\author{
Mounir Adnane ${ }^{1,2}$, Paul Kelly ${ }^{1}$, Aspinas Chapwanya ${ }^{3}$, Kieran G. Meade ${ }^{4,5^{*}}$ and Cliona O'Farrelly ${ }^{1}$
}

\begin{abstract}
Background: In the postpartum cow, early diagnosis of uterine disease is currently problematic due to the lack of reliable, non-invasive diagnostic methods. Cervico-vaginal mucus (CVM) is an easy to collect potentially informative source of biomarkers for the diagnosis and prognosis of uterine disease in cows. Here, we report an improved method for processing CVM from postpartum dairy cows for the measurement of immune biomarkers. CVM samples were collected from the vagina using gloved hand during the first two weeks postpartum and processed with buffer alone or buffer containing different concentrations of the reducing agents recommended in standard protocols: Dithiothriotol (DTT) or N-Acetyl-L-Cysteine (NAC). Total protein was measured using the bicinchoninic acid (BCA) assay; interleukin 6 (IL-6), IL-8 and a1-acid glycoprotein (AGP) were measured by ELISA.

Results: We found that use of reducing agents to liquefy CVM affects protein yield and the accuracy of biomarker detection. Our improved protocol results in lower protein yields but improved detection of cytokines and chemokines. Using our modified method to measure AGP in CVM we found raised levels of AGP at seven days postpartum in CVM from cows that went on to develop endometritis.

Conclusion: We conclude that processing CVM without reducing agents improves detection of biomarkers that reflect uterine health in cattle. We propose that measurement of AGP in CVM during the first week postpartum may identify cows at risk of developing clinical endometritis.
\end{abstract}

Keywords: Cervico-vaginal mucus, Postpartum, Reducing agent, Endometritis, Biomarker

\section{Background}

The postpartum bovine uterus is susceptible to diverse pathologies including viral and bacterial infection as well as endometritis, all of which impact negatively on the health, productivity and fertility of cows [1-3]. Current diagnostic methods for predicting uterine inflammation such as uterine cytology and biopsy require specialist expertise and invasive tools. In contrast, CVM could provide a useful resource for the analysis of uterine health. CVM is composed of a mixture of oviductal, uterine, cervical and vaginal secretions and their production is influenced by health status, the microbiome and pregnancy $[2,4,5]$.

\footnotetext{
* Correspondence: kieran.meade@teagasc.ie

${ }^{4}$ Animal \& Bioscience Research Department, Animal \& Grassland Research and Innovation Centre, Teagasc, Grange, Co. Meath, Ireland

${ }^{5}$ Immunogenetics \& Animal Health, Animal \& Grassland Research and

Innovation Centre, Teagasc, Grange, Co. Meath, Ireland

Full list of author information is available at the end of the article
}

Biomolecules in CVM reflect the health and secretions of the uterus and CVM could therefore substitute for more invasive analyses.

Cytokines, e.g. interleukin 6 (IL-6), chemokines e.g. IL-8 and acute phase proteins e.g. $\alpha 1$-Acid Glycoprotein (AGP), produced by endometrial epithelial cells and local immune populations are increased in inflamed uterine tissue and in vitro models [6-8]. These inflammatory biomarkers have been detected in uterine mucus and CVM [8-10]. Due to the physical properties of mucus, processing of CVM with reducing agents is routinely recommended before the analysis of soluble-phase biomarkers $[4,9,11]$. N-acetyl-L-cysteine (NAC) and Dithiothreitol (DTT) are commonly used to homogenize mucus by reducing the disulfide bonds of mucins [12-14]. However, many immune biomarkers also have disulfide bonds $[15,16]$ and their detection is likely to be compromised by use of reducing agents. The overall objective of the

(c) The Author(s). 2018 Open Access This article is distributed under the terms of the Creative Commons Attribution 4.0 International License (http://creativecommons.org/licenses/by/4.0/), which permits unrestricted use, distribution, and 
current study is to improve processing of postpartum CVM for measuring candidate biomarkers that may predict uterine inflammation and disease.

\section{Results}

\section{Total protein and SDS-PAGE electrophoresis}

The standard protocol (with DTT) resulted in higher levels of total protein than the modified protocol (Fig. 1a).

To determine which protocol best preserves the integrity of proteins with molecular weights of the candidate cytokines, protocols were compared based on the protein pattern within the range of $10-35 \mathrm{KDa}$ (Fig. 2b) and results are shown in Fig. 2a (red box). Furthermore, processing mucus without reducing agent gave denser band patterns for proteins with large molecular weight (> $130 \mathrm{KDa}$ ).

\section{Measurement IL6, IL8 and AGP}

Our modified protocol resulted in the detection of significantly higher levels of both IL-6 and IL-8 in postpartum CVM per $\mathrm{ml}$ of mucus $(P<0.001)$ (Fig. $1 \mathrm{~b}$ and $\mathrm{c}$ ). Accounting for total protein concentration in each sample, the concentration of IL-6 and IL- 8 per mg of total protein was also significantly higher in the modified protocol compared to the standard protocol $(P<0.001)$ (Fig. 1d and e).

AGP levels in CVM processed without reducing agent were higher in cows which went on to develop clinical endometritis compared to healthy cows $(P<0.05)$ (Fig. 3$)$.

\section{Discussion}

Here we demonstrated that use of reducing agents during the processing of CVM impacts on the accurate detection of proteins and biomarkers. The standard protocol (with DTT) resulted in higher levels of total protein than the modified protocol, since DTT is a powerful reducing agent that homogenizes mucus through the reduction of disulfide bounds. Due to the low level of circulating estrogen, postpartum mucus is characterized by high viscosity $[5,17]$. For this reason, we believe that DTT used in standard protocols resulted in higher levels of total protein as it helped to breakdown disulfide bonds of the viscous mucins and made protein accessible for measurement by BCA assay. Thus, if for any reason the use of reducing agent is required, it is important to determine the lowest concentration that does not interfere with the marker being assessed.

SDS-PAGE confirmed that use of reducing agent affected the stability of proteins in CVM. CVM samples were run using non-reducing loading buffer to limit interaction with the effect of the reducing agent used for processing mucus. Within the molecular weight range of the main inflammatory cytokines, the protein bands were denser in the modified protocol indicating that they contain higher levels of proteins at this molecular weight. SDS-PAGE shown that for high molecular weight proteins, such as acute phase proteins and mucins, both reducing agents should be avoided as these
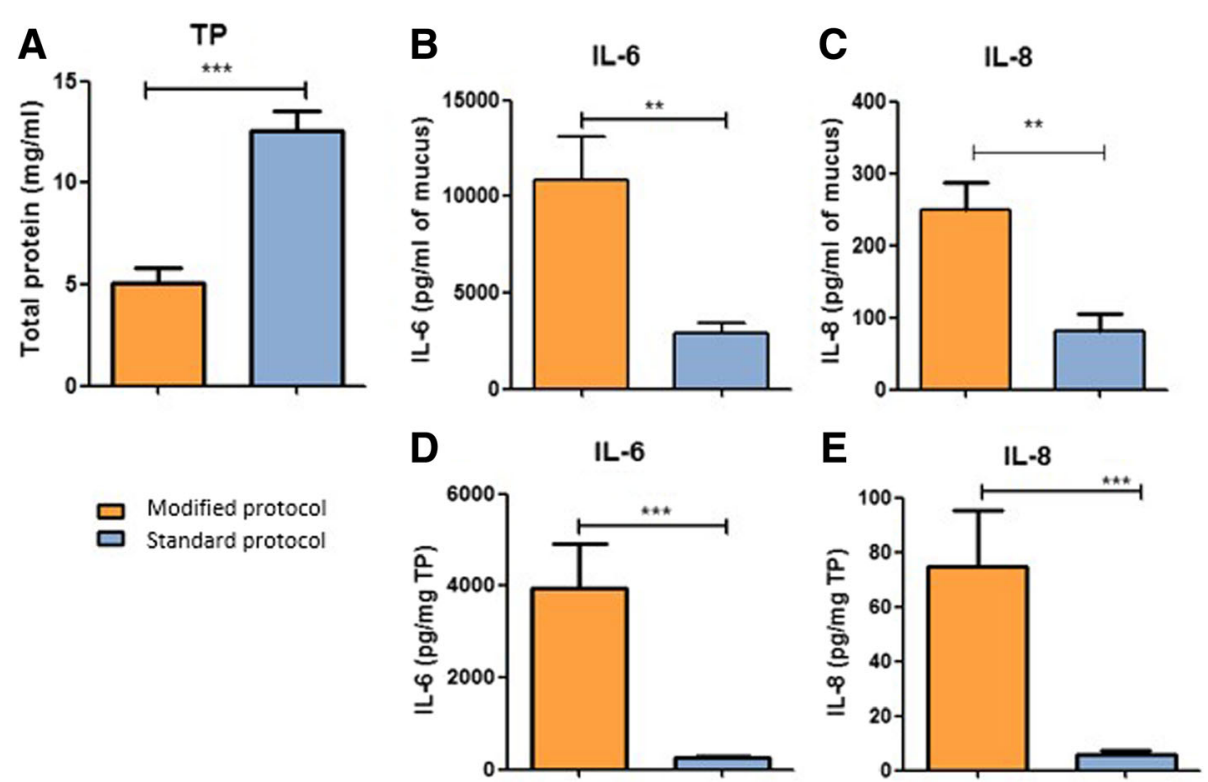

Fig. 1 a Total protein levels in CVM from 16 cows at first two weeks postpartum were measured using BCA assay and compared between our modified protocol and the standard protocol (with DTT). b, c IL-6 and IL-8 levels were measured by ELISA and results were presented according to the volume of mucus analyzed. $\mathbf{d}$, e taking in consideration the amount of total protein (TP) in CVM, IL-6 and IL-8 levels were presented per $\mathrm{mg}$ of total protein in the mucus. Results are presented as mean \pm SEM and analyzed by $t$ test. Significant differences between groups are calculated. ${ }^{* *} P<0.001,{ }^{* *} P<0.01$ and ${ }^{*} P<0.05$ 


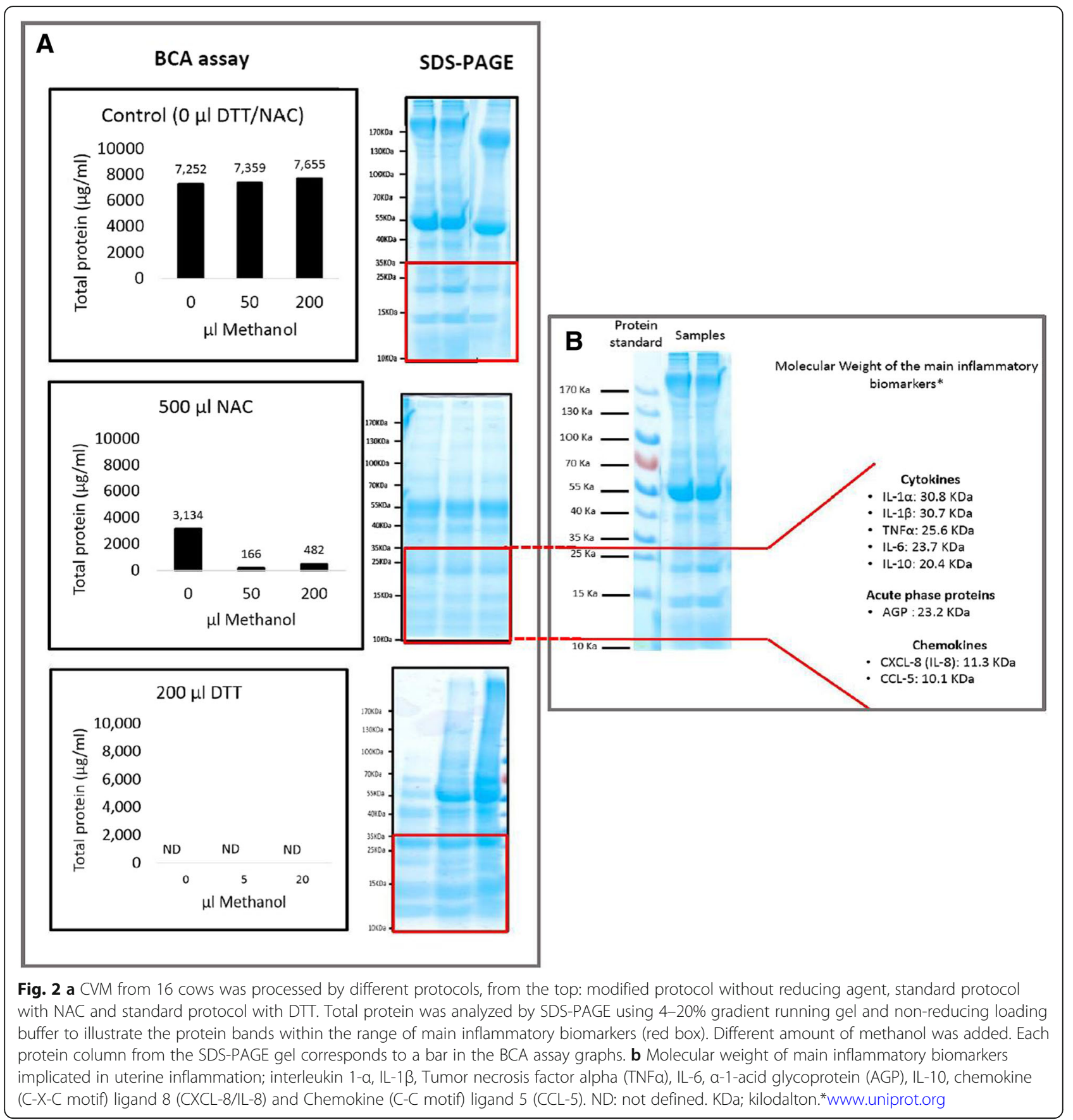

biomarkers would be reduced and degraded and could not be accurately measured by ELISA.

Our modified protocol resulted in the detection of significantly higher levels of both IL- 6 and IL- 8 in postpartum CVM. As proteins, cytokines, chemokines and acute phase proteins contain disulfide bonds between the cysteine residues, and the use of reducing agent may affect the stability of these proteins and decrease their detection using ELISA technique. For example, the IL-6 protein contains 4 cysteine residues, which are conserved between different species (i.e. human and cow) and are connected by 2 disulfide bonds (Cys 44-Cys 50 and Cys 73-Cys 83) [18, 19]. The two disulfide bridges can be reduced and alkylated under chemical reduction [20] or non-denaturing conditions [21]. Therefore, reducing agents decrease the stability of IL-6 and may decrease its detection by antibodies, since the disulfide bonds seem to be responsible for maintaining structural integrity of receptor binding sites rather than conformational stability $[20,21]$. In a previous study at 


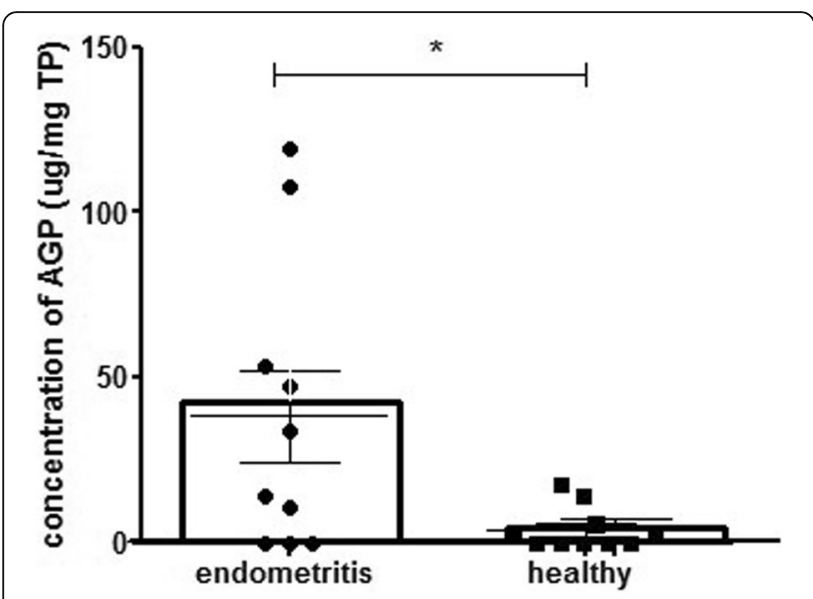

Fig. 3 CVM mucus from 20 cows at 7 days postpartum was processed without reducing agent and a1-acide glycoprotein (AGP) levels were measured using ELISA. AGP level was presented according to the amount of total protein (TP) in CVM. Results are presented as mean \pm SEM and analyzed by $t$ test. Significant differences between groups are calculated. ${ }^{*} P<0.05$

high concentrations, DTT decreased by $43 \%$ the detectable concentration of IL-6 standard [15]. Likewise, IL- 8 contains 4 cysteines that form 2 disulfide bonds and it is rapidly inactivated when their disulfide bonds are reduced [22] which would decrease its detection by ELISA.

Increased AGP levels are associated with uterine infection and have been proposed to be prognostic of endometritis [23, 24]. To validate our improved protocol to identify pathological inflammation, AGP was measured in CVM collected at seven days postpartum from 20 cows, 10 of which went on to develop endometritis. CVM processed with the modified protocol resulted in higher levels of AGP in cows which went on to develop clinical endometritis, compared to healthy cows. AGP has two disulfide bounds between cysteine (Cys) Cys5-Cys165 and Cys72-Cys147 [25] and use of reducing agent would breakdown these bounds and decrease the detection of AGP. Likewise, DTT was confirmed to reduce the molecular weight of pig AGP when it used for 2D electrophoresis [26]. Using our improved protocol to measure AGP in CVM to predict cows at risk of developing clinical endometritis, we found that the test could have a sensitivity of $70 \%$ and specificity of $100 \%$. Thus, all cows positively identified at day 7 developed clinical endometritis at 21 DPP. These findings could help to reduce antibiotic use by reducing the numbers of cattle treated using CVM diagnosis alone, as well as reducing the costs associated with reproductive diseases.

\section{Conclusion}

Here we show that processing CVM without any reducing agent allows for more accurate measurement of inflammatory biomarkers in early postpartum mucus. We also show that raised AGP levels predict cows at risk of developing clinical endometritis. Thus, the improved detection of biomarkers in CVM from the postpartum cow represents a technique with significant practical utility for early disease diagnosis in a non-invasive and welfare friendly manner.

\section{Methods}

\section{Herd identification}

Material was obtained from 36 mixed-parity HolsteinFriesian dairy cows during their first two weeks postpartum. Animals used in this study belong to three commercial dairy farms. Among these cows, 16 belong to one farm were used to measure IL- 6 and IL- 8 , and 20 cows from two different farms were diagnosed for clinical endometritis by scoring mucus aspect and odor at day 21 postpartum [24] and used to measure AGP levels. All animals were examined in their normal farming conditions and they remain on farm after the samples were collected.

\section{Vaginal mucus collection}

Vaginal examination and mucus collection were performed according to a previously described protocol [27]. Briefly, using examination sleeves, the perineum was wiped and washed with $70 \%$ ethanol to remove fecal material. An examination sleeve was covered with clean surgical glove and the gloved hand was inserted through the vulva into the vagina and CVM was collected and scored as described by Williams et al. (2005). CVM was collected in an empty sterile $20 \mathrm{ml}$ tube and immediately placed on ice and transported to the laboratory within 4-6 h.

\section{CVM processing}

CVM collected from 16 cows from one farm was used to optimize the technique and processed using two different protocols: the standard protocol using reducing agent (DTT) $[9,15]$ and our modified protocol without reducing agent. In the modified protocol, CVM was centrifuged at $3000 \mathrm{x} \mathrm{g}$ for $15 \mathrm{~min}$ at $4{ }^{\circ} \mathrm{C}$ and $500 \mu \mathrm{l}$ of the upper part was collected and mixed with $1000 \mu \mathrm{l}$ of sterile PBS in $2 \mathrm{ml}$ eppendorf tubes and vortexed. In the standard protocol (with DTT), CVM was processed according to Cronin et al. (2010). Briefly, $2 \mathrm{~g}$ of frozen CVM was added to $10 \mathrm{ml}$ of cytolyt solution (40\% methanol: $60 \%$ distilled water) and mixed with $1 \mathrm{mM}$ DTT to disrupt the mucus. Tubes were then centrifuged at $3000 \mathrm{x}$ g for $15 \mathrm{~min}$ at $4{ }^{\circ} \mathrm{C}$. The supernatant was collected and multiple aliquots of $1 \mathrm{ml}$ were prepared and used to measure IL-6, IL- 8 and AGP by ELISA.

CVM from one cow was selected for further analysis using a second reducing agent NAC [15]. In the modified protocol, $500 \mathrm{mg}$ from frozen CVM were mixed with $1000 \mu \mathrm{l}$ of PBS. In the standard protocol, $500 \mathrm{mg}$ of frozen CVM were mixed with $1000 \mu \mathrm{l}$ PBS in $5 \mathrm{ml}$ tubes 
and different volumes of $1 \mathrm{mM} \mathrm{NAC} \mathrm{(50,100,} \mathrm{200,} \mathrm{300,}$ $500 \mu \mathrm{l})$ or DTT $(20,50,100,200 \mu \mathrm{l})$ were added to each tube. Tubes were centrifuged at $3000 \mathrm{x} \mathrm{g}$ at $4{ }^{\circ} \mathrm{C}$ for $15 \mathrm{~min}$ and the supernatant was collected and aliquoted into Eppendorf tubes and stored at $-80{ }^{\circ} \mathrm{C}$ for further analysis by BCA assay for total protein and SDS-PAGE.

\section{Measurement of total protein}

Total protein levels in CVM were measured using a bicinchoninic acid (BCA) assay using a commercially available kit (Pierce $^{\mathrm{rm}}$ BCA Protein Assay Kit (\#23227, ThermoScientific $^{\circ}, 3747$ N. Meridian Rd. Rockford, IL 61101, United States) according to manufacturer's guidelines. Briefly, the contents of one albumin standard (BSA) ampule was diluted with PBS into eight standards and one blank. The working reagent was prepared by mixing 50 parts of $\mathrm{BCA}$ reagent $\mathrm{A}$ with 1 part of $\mathrm{BCA}$ reagent B (50:1, Reagent A: B). Then, $25 \mu \mathrm{L}$ of each standard or sample were added in duplicate into a microplate well. $200 \mu \mathrm{L}$ of the working reagent was added to each well and the 96 well plate was mixed thoroughly on a plate shaker for $30 \mathrm{~s}$. The plate was then covered and incubated at $37{ }^{\circ} \mathrm{C}$ for $30 \mathrm{~min}$. After cooling the plate, the absorbance was measured at $562 \mathrm{~nm}$ on a plate reader (GloMax ${ }^{\oplus}$-Multi Detection System, Promega Corporation, 2800 Woods Hollow Road Madison, WI 53711 USA).

\section{SDS-PAGE electrophoresis}

To visualize the range of proteins in mucus, a gradient running gel $4-20 \%$ was chosen in combination with a $5 \%$ stacking gel. To not interact with the effect of the reducing agent added to the mucus, samples were loaded in the gel cassette using non-reducing loading buffer. Gels were run at $110 \mathrm{~V}$ for $90 \mathrm{~min}$ and then stained with Coomassie blue G250 for one hour with gentle agitation. After overnight distaining in 10\% glacial acetic acid, gels were scanned and interpreted.

\section{Measurement IL6, IL8 and AGP}

After thawing, samples were centrifuged at $3000 \mathrm{x}$ g for $15 \mathrm{~min}$ at $4{ }^{\circ} \mathrm{C}$ and the supernatant was used to measure biomarkers. Levels of IL-6, IL-8 and AGP in CVM were measured using commercial ELISA kits (human IL-8 ELISA kit: R\&D Systems Inc., Minneapolis, Minnesota, USA; bovine IL-6 ELISA kit: \#ESS0029, ThermoScientific $^{\circ}, 3747$ N. Meridian Rd. Rockford, IL 61101; Cow AGP: \#AGP-11, Life Diagnostics Inc. ${ }^{\circ}$, P.O. Box 5205, West Chester, Pa. 19380) according to the guidelines provided by the manufacturers and modified according to previous studies in bovine $[6,9,10]$. Human IL-8 ELISA was used because no bovine specific IL- 8 ready-to-use ELISA is commercially available. Furthermore, the antibodies used in the kit have been confirmed to cross-react with bovine IL-8 $[6,28]$. To validate the usefulness of the improved protocol to detect uterine health problems, AGP was measured in CVM from 20 animals of which 10 developed clinical endometritis.

\section{Statistical analysis}

Statistical analysis was performed using GraphPad ${ }^{\circ}$ Prism 5 software (GraphPad Software, Inc. 7825 Fay Avenue, Suite 230 La Jolla, CA 92037 USA). A Students $t$ test was used to compare results between two groups, while one-way ANOVA with Bonferroni post-comparison test was used to compare between three or more groups. Results were presented as mean \pm SEM and considered statistically significant at $P$-value $<0.05$.

\section{Abbreviations}

AGP: a1-acid glycoprotein; BCA assay: Bicinchoninic acid assay; CVM: Cervicovaginal mucus; Cys: Cysteine; DTT: Dithiothriotol; ELISA: Enzyme-linked immunosorbent assay; IL: Interleukin; NAC: N-Acetyl-L-Cysteine; SDSPAGE: Sodium dodecyl sulfate polyacrylamide gel electrophoresis; SEM: Standard error of the mean

\section{Acknowledgements}

The authors acknowledge helpful collaboration from the O'Farrelly and Meade laboratory members.

\section{Funding}

This work was supported by scholarship from The Algerian Ministry for High Education and Scientific Research and University of Tiaret, Algeria by funding the one-year research visit of MA, and by a grant ofarrecl-HRB-HRA_POR/ 2012/37 for funding the reagents and material used during the experiment. Funding to KGM and CO'F was also provided by the Irish Department of Agriculture, Food and the Marine (Stimulus 13/S/472).

\section{Availability of data and materials}

The datasets used and/or analysed during the current study available from the corresponding author on reasonable request.

\section{Authors' contributions}

Conceived and designed the experiments: COF, KGM, AC and MA. Sample collection and performed the experiments: MA. Analyzed the data: MA. Contributed to the writing: COF, KGM, AC, MA and PK. All authors have read and approved the final manuscript.

\section{Ethics approval and consent to participate}

CVM samples were collected with ethical approval and under license, both issued from the Health Products Regulatory Authority in Ireland; and with verbal agreement with the farm owner. Written agreement is not required under current ethics regulations.

Consent for publication

Not applicable.

Competing interests

The authors declare that they have no competing interests.

\section{Publisher's Note}

Springer Nature remains neutral with regard to jurisdictional claims in published maps and institutional affiliations.

\section{Author details}

${ }^{1}$ Comparative Immunology Group, School of Biochemistry and Immunology, Trinity College, Dublin, Ireland. ${ }^{2}$ Institute of Veterinary Sciences, Tiaret, Algeria. ${ }^{3}$ Department of Clinical Sciences, Ross University School of Veterinary Medicine, Basseterre, West Indies, St. Kitts and Nevis. ${ }^{4}$ Animal \& Bioscience Research Department, Animal \& Grassland Research and Innovation Centre, 
Teagasc, Grange, Co. Meath, Ireland. ${ }^{5}$ Immunogenetics \& Animal Health, Animal \& Grassland Research and Innovation Centre, Teagasc, Grange, Co. Meath, Ireland.

Received: 27 June 2018 Accepted: 16 September 2018

Published online: 29 September 2018

\section{References}

1. Sheldon IM, Lewis GS, LeBlanc S, Gilbert RO. Defining postpartum uterine disease in cattle. Theriogenology. 2006;65:1516-30

2. Sheldon IM, Price SB, Cronin J, Gilbert RO, Gadsby JE. Mechanisms of infertility associated with clinical and subclinical endometritis in high producing dairy cattle. Reprod Domest Anim. 2009:44(Suppl 3):1-9.

3. LeBlanc SJ, Duffield TF, Leslie KE, Bateman KG, Keefe GP, Walton JS, Johnson WH. Defining and diagnosing postpartum clinical endometritis and its impact on reproductive performance in dairy cows. J Dairy Sci. 2002:85:2223-36.

4. Zegels G, Van Raemdonck GA, Tjalma WA, Van Ostade XW. Use of cervicovaginal fluid for the identification of biomarkers for pathologies of the female genital tract. Proteome Sci. 2010;8:63.

5. Lopez-Gatius F, Miro J, Sebastian I, Ibarz A, Labernia J. Rheological properties of the anterior vaginal fluid from superovulated dairy heifers at estrus. Theriogenology. 1993;40:167-80.

6. Foley C, Chapwanya A, Callanan JJ, Whiston R, Miranda-CasoLuengo R, Lu J, Meijer WG, Lynn DJ, O'Farrelly C, Meade KG. Integrated analysis of the local and systemic changes preceding the development of post-partum cytological endometritis. BMC Genomics. 2015;16:811.

7. Chapwanya A, Meade KG, Foley C, Narciandi F, Evans AC, Doherty ML, Callanan JJ, O'Farrelly C. The postpartum endometrial inflammatory response: a normal physiological event with potential implications for bovine fertility. Reprod Fertil Dev. 2012;24:1028-39.

8. Brodzki P, Kostro K, Brodzki A, Wawron W, Marczuk J, Kurek L. Inflammatory cytokines and acute-phase proteins concentrations in the peripheral blood and uterus of cows that developed endometritis during early postpartum. Theriogenology. 2015:84:11-8.

9. Cronin JG, Hodges R, Pedersen S, Sheldon IM. Enzyme linked immunosorbent assay for quantification of bovine interleukin-8 to study infection and immunity in the female genital tract. Am J Reprod Immunol. 2015;73:372-82

10. Kim IH, Kang HG, Jeong JK, Hur TY, Jung YH. Inflammatory cytokine concentrations in uterine flush and serum samples from dairy cows with clinical or subclinical endometritis. Theriogenology. 2014;82:427-32.

11. Van Raemdonck GA, Tjalma WA, Coen EP, Depuydt CE, Van Ostade XW. Identification of protein biomarkers for cervical cancer using human cervicovaginal fluid. PLoS One. 2014;9:e106488

12. Kelly MM, Leigh R, Horsewood P, Gleich GJ, Cox G, Hargreave FE. Induced sputum: validity of fluid-phase IL-5 measurement. J Allergy Clin Immunol. 2000;105:1162-8

13. Saraswathy Veena V, Sara George P, Jayasree K, Sujathan K. Comparative analysis of cell morphology in sputum samples homogenized with dithiothreitol, N-acetyl-L cysteine, Cytorich((R)) red preservative and in cellblock preparations to enhance the sensitivity of sputum cytology for the diagnosis of lung cancer. Diagn Cytopathol. 2015;43:551-8.

14. Louis R, Shute J, Goldring K, Perks B, Lau L, Radermecker M, Djukanovic R. The effect of processing on inflammatory markers in induced sputum. Eur Respir J. 1999;13:660-7.

15. Woolhouse IS, Bayley DL, Stockley RA. Effect of sputum processing with dithiothreitol on the detection of inflammatory mediators in chronic bronchitis and bronchiectasis. Thorax. 2002:57:667-71.

16. Carr TF, Spangenberg A, Hill JL, Halonen MJ, Martinez FD. Effect of Dithiothreitol on sputum Interleukin-13 protein measurement. J Allergy Clin Immunol. 2015;135:AB179.

17. Tsiligianni T, Amiridis GS, Dovolou E, Menegatos I, Chadio S, Rizos D, Gutierrez-Adan A. Association between physical properties of cervical mucus and ovulation rate in superovulated cows. Can J Vet Res. 2011 75:248-53.

18. Simpson RJ, Hammacher A, Smith DK, Matthews JM, Ward LD. Interleukin-6: structure-function relationships. Protein Sci. 1997:6:929-55.

19. Clogston CL, Boone TC, Crandall BC, Mendiaz EA, Lu HS. Disulfide structures of human interleukin- 6 are similar to those of human granulocyte colony stimulating factor. Arch Biochem Biophys. 1989;272:144-51.
20. Zhang JG, Moritz RL, Reid GE, Ward LD, Simpson RJ. Purification and characterization of a recombinant murine interleukin-6. Isolation of $\mathrm{N}$ - and C-terminally truncated forms. Eur J Biochem. 1992;207:903-13.

21. Rock FL, Li X, Chong P, Ida N, Klein M. Roles of disulfide bonds in recombinant human interleukin 6 conformation. Biochemistry. 1994;33: $5146-54$.

22. Baggiolini M, Walz A, Kunkel SL. Neutrophil-activating peptide-1/interleukin 8, a novel cytokine that activates neutrophils. J Clin Invest. 1989;84:1045-9.

23. Sheldon IM, Noakes DE, Rycroft A, Dobson H. Acute phase protein responses to uterine bacterial contamination in cattle after calving. Vet Rec. 2001;148:172-5

24. Williams EJ, Fischer DP, Pfeiffer DU, England GC, Noakes DE, Dobson H, Sheldon IM. Clinical evaluation of postpartum vaginal mucus reflects uterine bacterial infection and the immune response in cattle. Theriogenology. 2005:63:102-17.

25. Schmid K, Burgi W, Collins JH, Nanno S. The disulfide bonds of alpha1-acid glycoprotein. Biochemistry. 1974;13:2694-7.

26. Heegaard PMH, Miller I, Sorensen NS, Soerensen KE, Skovgaard K. Pig a(1)acid glycoprotein: characterization and first description in any species as a negative acute phase protein. PLoS One. 2013;8:e68110.

27. Adnane M, Chapwanya A, Kaidi R, Meade KG, O'Farrelly C. Profiling inflammatory biomarkers in cervico-vaginal mucus (CVM) postpartum: potential early indicators of bovine clinical endometritis? Theriogenology. 2017:103:117-22

28. Shuster DE, Kehrli ME Jr, Rainard P, Paape M. Complement fragment C5a and inflammatory cytokines in neutrophil recruitment during intramammary infection with Escherichia coli. Infect Immun. 1997:65:3286-92.
Ready to submit your research? Choose BMC and benefit from:

- fast, convenient online submission

- thorough peer review by experienced researchers in your field

- rapid publication on acceptance

- support for research data, including large and complex data types

- gold Open Access which fosters wider collaboration and increased citations

- maximum visibility for your research: over $100 \mathrm{M}$ website views per year

At BMC, research is always in progress.

Learn more biomedcentral.com/submissions 